\title{
A RELAÇÃO DA POSTURA CORPORAL COM A PROSÓDIANA DOENÇA DE PARKINSON: ESTUDO DE CASO
}

\author{
The relations between body posture and prosody in Parkinson's \\ disease: case study
}

\begin{abstract}
Fernanda Vargas Ferreira (1), Ana Lúcia Cervi Prado (2), Carla Aparecida Cielo ${ }^{(3)}$, Angela Ruviaro Busanello ${ }^{(4)}$
\end{abstract}

\begin{abstract}
RESUMO
Objetivo: investigar a associação entre a postura corporal e a prosódia em indivíduos com Doença de Parkinson. Métodos: estudo de corte transversal realizado com cinco sujeitos com Doença de Parkinson da cidade de Santa Maria, Estado do Rio Grande do Sul, em 2006. Utilizaram-se avaliações da prosódia lingüística e emocional bem como da postura corporal. A análise estatística utilizada foi descritiva. Resultados: foram estudados quatro sujeitos do sexo masculino e um sujeito do sexo feminino com idades entre 37 e 53 anos. Três sujeitos encontravam-se no estágio I, um sujeito no estágio III e um sujeito no estágio IV da doença conforme a escala de classificação da função motora Hohen \&Yahr, todos sob o uso de medicação e apresentando os sinais da tríade característica da patologia (rigidez, tremor, bradicinesia) bem como as alterações posturais típicas. Na comparação entre prosódia emocional e prosódia lingüística, encontrou-se melhor desempenho na prosódia emocional e não se evidenciou associação entre os estágios da patologia e alterações na postura corporal e prosódia. Conclusão: as alterações posturais são sinais característicos da Doença de Parkinson, assim como alterações na prosódia lingüística e emocional. A ocorrência de alterações posturais foi elevada entre os parkinsonianos. Os sujeitos apresentaram melhor performance na prosódia emocional. Não houve evidências de que os estágios da doença estivessem associados às alterações da prosódia e da postura corporal.
\end{abstract}

DESCRITORES: Estudos Transversais; Doença de Parkinson; Postura; Modalidades de Fisioterapia; Fonoterapia

(1) Fisioterapeuta; Professora Substituta do Departamento de Fisioterapia e Reabilitação da Universidade Federal de Santa Maria; Mestranda em Distúrbios da Comunicação Humana pela Universidade Federal de Santa Maria - RS.

(2) Fisioterapeuta; Professora Assistente do Departamento de Fisioterapia e Reabilitação da Universidade Federal de Santa Maria; Doutoranda pela Universidade de Brasília - DF.

(3) Fonoaudióloga; Professora Adjunta do Departamento de Fonoaudiologia da Universidade Federal de Santa Maria; Doutora em Lingüística Aplicada pela Pontifícia Católica do Rio Grande do Sul - RS.

(4) Fonoaudióloga; Professora Substituta do Departamento de Fonoaudiologia da Universidade Federal de Santa Maria; Mestranda em Distúrbios da Comunicação Humana pela Universidade Federal de Santa Maria - RS.

Departamento de Fisioterapia e Reabilitação. Universidade Federal de Santa Maria (UFSM). Santa Maria, RS, Brasil. Baseado em monografia de especialização apresentada ao Programa de Pós-Graduação em Abordagem Corporal Interdisciplinar em Fisioterapia da Universidade Federal de Santa Maria, 2006.

\section{INTRODUÇÃO}

A Doença de Parkinson (DP) é uma doença neurológica progressiva, idiopática que afeta igualmente homens e mulheres, na maioria das vezes após os 50 anos ${ }^{1-3}$. As principais manifestações são: tremor de repouso, rigidez, bradicinesia, alterações posturais, marcha "festinada", hipomimia facial, depressão e alterações da qualidade da voz ${ }^{2-4}$.

A progressão dos sinais e sintomas da DP baseia-se na escala de Hoehn \& Yahr (HY - Degree of Disability Scale) criada em 1967, que indica o estado geral do paciente, sendo cinco estágios de doença. O estágio inicial é caracterizado por completa funcionalidade, tremor e rigidez unilateral; no estágio intermediário bilateralidade, bradicinesia, rigidez, alterações posturais; no estágio tardio, dependência funcional ${ }^{1-3}$.

Um dos principais comprometimentos na DP é 
a chamada "postura em flexão" que se caracteriza por flexão da cabeça, tronco ligeiramente inclinado para frente, semiflexão das articulações de joelhos, quadris e cotovelos, descrita desde 1817 por James Parkinson em seu ensaio sobre a doença ${ }^{3-5}$.

Os dois principais sinais que ocasionam alterações nos órgãos fonoarticulatórios são a rigidez e a bradicinesia os quais geram incoordenação nos movimentos destes órgãos ${ }^{4}$. Além destes, acredita-se que a postura em flexão, especialmente da cabeça e coluna cervical a qual se relaciona com a falta de harmonia e flexibilidade entre as estruturas do sistema estomatognático exerça a interrelação corpo-voz-fala.

As alterações fonoaudiológicas presentes na DP aumentam sua gravidade e freqüência de ocorrência com a duração e evolução da doença ${ }^{1-3}$. A fala motora se encontra comprometida devido à disartria hipocinética, que ocorre em cerca de $90 \%$ dos parkinsonianos e caracteriza-se por prejuízo peculiar da expressão verbal, redução da intensidade vocal, articulação imprecisa, disprosódia, disfluência, menor variação de freqüência fundamental, qualidade vocal alterada como rouquidão e soprosidade, diminuição ou aumento da velocidade, monotonia e tremor vocal ${ }^{1-5}$.

O objetivo deste estudo é investigar as alterações de comunicação que envolvem a fala na Doença de Parkinson e sua relação com a postura em flexão e prosódia, visto que, essa doença apresenta um caráter interdisciplinar por excelência, em virtude da variação sintomatológica e da necessidade de estudos que enfatizem a duração da doença, os estágios e a interface entre as principais repercussões fisioterapêuticas e fonoaudiológicas.

\section{MÉTODOS}

O presente estudo não-experimental caracterizou-se pela análise quanti-qualitativa, transversal, através do levantamento dos dados em campo, realizado na cidade de Santa Maria, RS, de junho a agosto de 2006. Foram voluntários 10 sujeitos de ambos os sexos com diagnóstico neurológico de Doença de Parkinson Idiopática com idade entre 37 e 53 anos falantes do português brasileiro e submetidos às avaliações, cujos resultados foram utilizados como critérios de exclusão: avaliação otorrinolaringológica (a fim de excluir os sujeitos com possíveis lesões laríngeas), audiológica (com o intuito de eliminar a presença de perdas auditivas), do sistema estomatognático (cuja finalidade foi excluir aqueles que apresentassem alterações nos órgãos fonoarticulatórios que não as caracte- rísticas da doença), entrevista semi-estruturada que continha dados pessoais e informações acerca da patologia; a partir dos resultados das avaliações supracitadas, foram descartados cinco sujeitos.

Os cinco sujeitos que preencheram os critérios da pesquisa compuseram o grupo de estudo e foram submetidos, posteriormente, à avaliação da postura corporal e da prosódia.

A avaliação postural foi realizada com os sujeitos em trajes de banho (homens, sunga ou calção; mulheres, duas peças), na posição ereta, de frente e de perfil, posicionados diante de uma parede, sendo traçada uma linha vertical da cabeça aos pés, e linhas horizontais na altura dos segmentos corporais (linha do nariz, dos ombros, dos mamilos, dos quadris e dos joelhos), a fim de se conseguir um perfeito alinhamento desses segmentos. Os dados foram registrados por uma câmera fotográfica digital. Considerou-se a posição cérvico-escapular, as curvaturas da coluna vertebral, o posicionamento dos quadris, joelhos e pés, segundo os critérios de Kendall e Creary ${ }^{6}$.

A avaliação da prosódia (Figura 1 ) foi realizada individualmente em uma sala acusticamente tratada, abrangendo os aspectos prosódicos lingüísticos e emocionais. Todos os testes foram realizados em três seqüências fixas com a finalidade de eliminar os acertos e erros resultantes de formulações ao acaso.

Para a prosódia lingüística - linguagem espontânea solicitou-se ao sujeito que formulasse sentenças interrogativas, exclamativas e afirmativas a partir da apresentação de desenhos prédeterminados eliciadores destas frases. Já para a prosódia lingüística - linguagem automática foi solicitado ao sujeito que repetisse sentenças interrogativas, exclamativas e afirmativas (Você foi ao cinema ontem? Você quer pão ou bolo?, João vai à aula de física ou química?; Saia já da minha casa!, Não coma isso!, Que flor linda!; Eu fui ao cinema ontem., Eu quero bolo., Paula foi ao balé.).

Na avaliação da prosódia emocional foram utilizadas gravuras previamente determinadas para essa pesquisa, eliciadoras das emoções alegria, indignação, tristeza e raiva. O sujeito deveria expressar qual sentimento sentia ao ver as gravuras e formular sentenças de acordo com esse sentimento. Foram realizadas três seqüências, sendo que, cada uma das seqüências era constituída por três figuras (Figura 2).

Os resultados da avaliação prosódica foram categorizados em: (1) prosódia lingüística; e (2) prosódia emocional conforme a testagem descrita acima, (3) acentuação (adequada ou inadequada, conforme a observação das tarefas solicita- 
das e da possível diferença entre a fala espontânea e automática), (4) entonação (adequada ou inadequada, conforme as frases interrogativa, exclamativa e afirmativa e da possível diferença entre a fala espontânea e automática), (5) velocidade da fala (normal, aumentada, diminuída, muito variada, e da diferença entre a fala espontânea e a automática), (6) fluência da fala (tipo adequado ou inadequado e também a possível diferença na fala espontânea e automática). Os dados foram coletados uma hora após administração da medicação (período ON- sob o efeito das medicações sintomáticas, sendo especialmente considerada a levodopa) e registrados em um gravador de voz.

A pesquisa foi aprovada pelo Comitê de Ética em Pesquisa da Universidade Federal de Santa Maria RS, sob o $n^{\circ} 016722$.

A análise dos dados coletados foi realizada de forma descritiva, observando-se as tendências apresentadas pelo grupo tanto nos resultados da avaliação postural e de prosódia isoladamente, quanto na relação entre ambos.

\section{RESULTADOS}

A amostra final constituiu-se de cinco indivíduos, sendo quatro homens e uma mulher, na faixa etária entre 37 e 53 anos, classificados no Estágio I de Hohen \& Yahr; Estágio III e Estágio IV e todos submetidos à avaliação da prosódia e da postura corporal. Os sujeitos foram agrupados pelos estágios da doença, a fim de reduzir a heterogeneidade dentro do próprio grupo e facilitar a análise dos dados.

Individualmente observaram-se as seguintes características como segue.

Sujeito 1 (S1), sexo masculino, 45 anos, há 12 anos com diagnóstico de DP; foi classificado quanto ao Estágio Hoehn \& Yahr $=1$. Os achados encontrados foram: sintomatologia unilateral (hemicorpo esquerdo), rigidez, tremor, bradicinesia, instabilidade postural, dificuldades para realizar movimentos, marcha festinada e relato de depressão.

Sujeito 2 (S2), sexo masculino, 52 anos, há cinco anos com diagnóstico de DP; encontra-se classificado segundo os Estágios Hoehn \& Yahr $=4$. Os achados encontrados foram: sintomatologia bilateral, rigidez, tremor, bradicinesia, instabilidade postural, dificuldades para realizar movimentos e relato de depressão.

Sujeito 3 (S3), sexo feminino, 52 anos, há cinco anos com diagnóstico de DP, foi classificado segundo os Estágios Hoehn \& Yahr =1. Os achados encontrados foram: sintomatologia unilateral (hemicorpo direito), rigidez, tremor, bradicinesia, instabilidade postural, dificuldades para realizar movimentos e relato de depressão.

Sujeito 4 (S4), sexo masculino, 53 anos, há dez anos com diagnóstico de DP; quanto ao Estágio Hoehn \& Yahr $=3$. Seus resultados foram: sintomatologia bilateral, rigidez, tremor, bradicinesia, instabilidade postural, dificuldades para realizar movimentos, marcha festinada e relato de depressão.

Sujeito 5 (S5), sexo masculino, 37 anos, há quatro anos com diagnóstico de DP; quanto ao Estágio Hoehn \& Yahr $=1$. Seus resultados foram: sintomatologia unilateral (hemicorpo esquerdo), rigidez, tremor, bradicinesia, dificuldades para realizar movimentos, marcha festinada e relato de depressão.

Portanto, todos os sujeitos apresentaram sinais e sintomas referentes à DP antes dos 50 anos; três sujeitos encontraram-se no Estágio 1; a tríade característica da DP foi relatada por todos os sujeitos que também referiram dificuldade em realizar movimentos; todos os sujeitos referiram depressão.

$\mathrm{Na}$ postura corporal todos apresentaram hiperlordose cervical com flexão da cabeça, quatro dos cinco sujeitos apresentaram hipercifose dorsal, quatro dos cinco sujeitos apresentaram protrusão de ombros (Tabela 1).

Quanto à prosódia lingüística, na fala espontânea, observou-se que três sujeitos (S1, S2, S4) apresentaram monotonia na sentença interro-gativa, três sujeitos (S1, S4, S5) apresentaram monotonia na sentença exclamativa, quatro sujeitos apresentaram adequação na sentença afirmativa (S2, S3, S4 e S5); ainda em relação à prosódia lingüística, porém na fala automática, todos os sujeitos apresentaram adequação (Tabela 2).

Em relação à prosódia emocional, no sentimento de alegria, três sujeitos (S3, S4 e S5) apresentaram alteração, no sentimento de indignação, um indivíduo (S5) evidenciou alteração; na tristeza, nenhum dos sujeitos apresentou alteração e, na raiva, apenas um indivíduo (S4) mostrou alteração (Tabela 3).

A entonação mostrou-se monótona nas sentenças interrogativas e exclamativas em três indivíduos (S1, S4, S5). Na velocidade de fala, observou-se que os sujeitos (S1, S2, S3, S5) não apresentaram alteração, apenas um (S4) mostrou lentidão. A fluência da fala apresentou-se adequada em quatro sujeitos (S2, S3, S4, S5), sendo que apenas em um sujeito (S1) houve disfluência. 


\section{FICHA DE AVALIAÇÃO DA PROSÓDIA}

1) Figuras (seqüência de apresentaçăo interrogativa/ exclamativa/ afirmativa)

Seqüência 1 -

Seqüência 2 -

Seqüência 3-

2) Emoçōes (seqüência de apresentação alegria/ indignação/ tristeza/ raiva)

Seqüência 1 -

Seqüência 2 -

Seqüência 3 -

3) Frases por imitação

3.1 - Interrogativas: Você foi ao cinema ontem?

Voce̊ quer påo ou bolo?

Joăo vai à aula de física ou química?

3.2 - Exclamativas: Saia já da minha casa!

Năo coma isso!

Que flor linda!

3.3 - Afirmativas : Eu fui ao cinema ontem.

Eu quero bolo.

Paula foi ao balé.

OBSERVAÇOัES

- Acentuaçắo: (....) adequada (...) Inadequada

(....) diferença entre fala automática e espontânea Quais?

- Entonação:

Frases interrogativas

(....) adequada (....) monótona (....) inadequada (não contextualizada)

Frases exclamativas

(....) adequada (....) monótona (...) inadequada (não contextualizada)

Frases afirmativas

(....) adequada (...) monótona (...) inadequada (não contextualizada

(....) diferença entre fala automática e espontânea

Quais?

- Velocidade: (....) normal (...) aumentada (...) diminuída (....) muito variada

(....) diferença entre fala automática e espontânea Quais?

- Fluência da Fala:

(....) diferença entre fala automática e espontånea

Quais?

OBSERVAÇŐES:

Figura 1 - Ficha de avaliação da prosódia

Rev CEFAC, São Paulo, v.9, n.3, 319-29, jul-set, 2007 

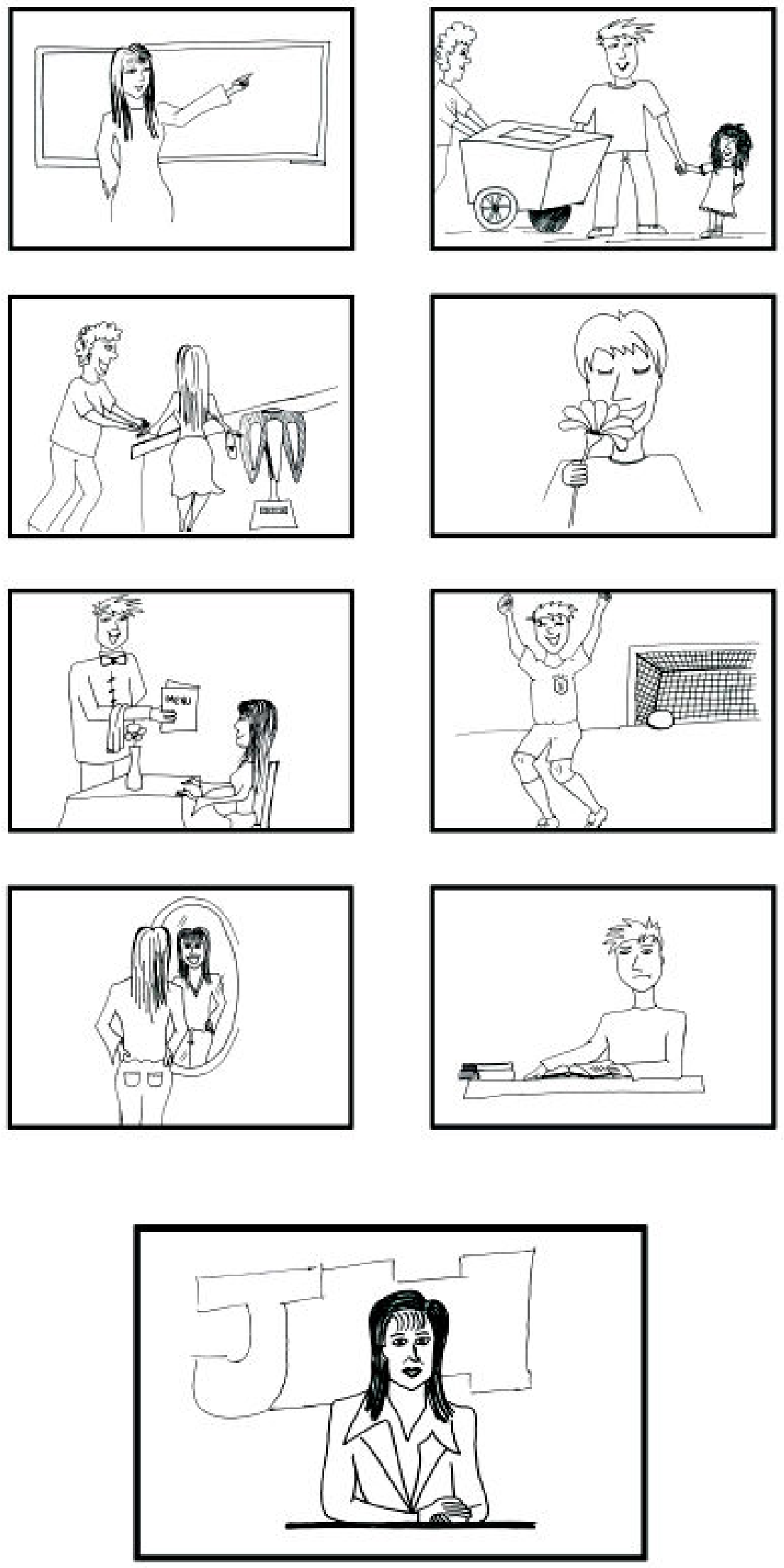

Figura 2 - Figuras utilizadas na avaliação da prosódia emocional 
Tabela 1 - Resultados das alterações posturais na coluna vertebral e segmentos corporais dos sujeitos

\begin{tabular}{|c|c|c|c|c|c|}
\hline Sujeitos & $\begin{array}{c}\text { Hiperlordose } \\
\text { Cervical }\end{array}$ & $\begin{array}{c}\text { Anteriorizaçāo } \\
\text { da cabeça }\end{array}$ & $\begin{array}{c}\text { Flexão } \\
\text { da cabeça }\end{array}$ & $\begin{array}{c}\text { Hipercifose } \\
\text { Dorsal }\end{array}$ & $\begin{array}{l}\text { Protração } \\
\text { de Ombros }\end{array}$ \\
\hline S1 & S & S & S & s & s \\
\hline S2 & S & S & S & S & S \\
\hline S3 & s & $\mathrm{s}$ & $\mathrm{s}$ & $\mathrm{N}$ & $\mathrm{s}$ \\
\hline S4 & S & $\mathrm{s}$ & $\mathrm{S}$ & s & $\mathrm{s}$ \\
\hline S5 & s & S & $\mathrm{N}$ & S & $\mathrm{N}$ \\
\hline
\end{tabular}

Tabela 2 - Resultados da prosódia lingüística dos sujeitos

\begin{tabular}{|c|c|c|c|c|}
\hline Sujeitos & Sequências & Interrogativa & Exclamativa & Afirmativa \\
\hline \multirow[t]{3}{*}{$\mathrm{S} 1$} & 1 & $M$ & $M$ & $\mathrm{~N}$ \\
\hline & 2 & M & M & $\mathrm{N}$ \\
\hline & 3 & M & A & $\mathrm{N}$ \\
\hline \multirow[t]{3}{*}{ S2 } & 1 & $\mathrm{~N}$ & $\mathrm{~N}$ & $\mathrm{~N}$ \\
\hline & 2 & $M$ & $\mathrm{~N}$ & $\mathrm{~N}$ \\
\hline & 3 & $M$ & $\mathrm{~N}$ & $\mathrm{~N}$ \\
\hline \multirow[t]{3}{*}{ S3 } & 1 & $\mathrm{~N}$ & $\mathrm{~N}$ & M \\
\hline & 2 & $M$ & । & $\mathrm{N}$ \\
\hline & 3 & $\mathrm{~N}$ & $\mathrm{~N}$ & $\mathrm{~N}$ \\
\hline \multirow[t]{3}{*}{ S4 } & 1 & M & M & $\mathrm{N}$ \\
\hline & 2 & A & M & $\mathrm{N}$ \\
\hline & 3 & $\mathrm{M}$ & $M$ & $\mathrm{~N}$ \\
\hline \multirow[t]{3}{*}{ S5 } & 1 & $\mathrm{~N}$ & M & $\mathrm{N}$ \\
\hline & 2 & M & M & $\mathrm{N}$ \\
\hline & 3 & $\mathrm{NR}^{*}$ & $N^{*}$ & $\mathrm{~N}$ \\
\hline
\end{tabular}

$\mathrm{M}=$ monótona; $\mathrm{N}=$ normal; $\mathrm{A}=$ afirmativa; $\mathrm{I}=$ interrogativa; $\mathrm{NR}^{*}=$ năo realizada 
Tabela 3 - Resultados da prosódia emocional dos sujeitos

\begin{tabular}{cccccc}
\hline Sujeitos & Sequências & Alegria & Indignaçăo & Tristeza & Raiva \\
\hline \multirow{2}{*}{ S1 } & 1 & $\mathrm{~N}$ & $\mathrm{~N}$ & $\mathrm{~N}$ & $\mathrm{~N}$ \\
& 2 & $\mathrm{~N}$ & $\mathrm{~N}$ & $\mathrm{~N}$ & $\mathrm{I}$ \\
& 3 & $\mathrm{~N}$ & $\mathrm{~N}$ & $\mathrm{~N}$ & $\mathrm{~N}$ \\
\hline S2 & 1 & $\mathrm{~N}$ & $\mathrm{~N}$ & $\mathrm{~N}$ & $\mathrm{~N}$ \\
& 2 & $\mathrm{~N}$ & $\mathrm{~N}$ & $\mathrm{~N}$ & $\mathrm{~N}$ \\
& 3 & $\mathrm{~N}$ & $\mathrm{~N}$ & $\mathrm{~N}$ & $\mathrm{M}$ \\
\hline S3 & 1 & $\mathrm{~N}$ & $\mathrm{~N}$ & $\mathrm{~N}$ & $\mathrm{~N}$ \\
& 2 & $\mathrm{~N}$ & $\mathrm{~N}$ & $\mathrm{~N}$ & $\mathrm{~N}$ \\
& 3 & $\mathrm{P}$ & $\mathrm{P}$ & $\mathrm{P}$ & $\mathrm{N}$ \\
\hline S4 & 1 & $\mathrm{~F}$ & $\mathrm{~F}$ & $\mathrm{~F}$ & $\mathrm{~N}$ \\
& 2 & $\mathrm{~L}$ & $\mathrm{~N}$ & $\mathrm{~N}$ & $\mathrm{D}$ \\
& 3 & $\mathrm{~N}$ & $\mathrm{~N}$ & $\mathrm{~N}$ & $\mathrm{D}$ \\
\hline S5 & 1 & $\mathrm{R}$ & $\mathrm{R}$ & $\mathrm{N}$ & $\mathrm{N}$ \\
& 2 & $\mathrm{~N}$ & $\mathrm{~N}$ & $\mathrm{~N}$ & $\mathrm{~N}$ \\
& 3 & $\mathrm{R}$ & $\mathrm{R}$ & $\mathrm{R}$ & $\mathrm{N}$ \\
\hline
\end{tabular}

$\mathrm{A}=$ alegria; $\mathrm{I}=$ indignaçăo; $\mathrm{T}=$ tristeza; $\mathrm{R}=$ raiva; $\mathrm{N}=$ normal; $\mathrm{O}=$ Ordem; $\mathrm{P}=$ pena; $\mathrm{L}=\mid$ localizaçăo; $\mathrm{F}=$ frustração; $\mathrm{D}=$ dúvida

\section{DISCUSSÃO}

A DP é uma patologia degenerativa que acomete igualmente homens e mulheres, na maioria das vezes após os 50 anos ${ }^{1,4,7}$. Neste estudo, todos os sujeitos apresentaram sinais e sintomas antes dessa idade. Em relação ao sexo, afirma-se que existe uma discreta predominância de ocorrência da DP nos homens ${ }^{8,9}$ estando em consonância com os dados desta pesquisa, na qual quatro sujeitos eram do sexo masculino e um do sexo feminino.

Em relação à evolução da sintomatologia, observouse que a DP e suas manifestações iniciam em um hemicorpo, o que ocorreu com a maioria dos sujeitos do grupo de estudo desta pesquisa, podendo passar progressivamente para o outro hemicorpo ou ambos ${ }^{2,9}$. Neste estudo, apenas $40 \%$ da amostra referiram o acometimento de ambos os lados, sendo que esta bilateralidade está relacionada aos estágios da doença.

Referente aos estágios, os dados desta pesquisa contrapõem-se a um estudo ${ }^{10}$ realizado com 58 pacientes portadores de DP, no qual houve predominân- cia de $38 \%$ de indivíduos no Estágio II, seguida por $24 \%$ no Estágio III; na presente pesquisa, três indivíduos apresentaram-se no Estágio I, entretanto, ressalta-se a diferença no número de indivíduos das amostras entre o presente estudo e o citado. Ainda, em outra pesquisa ${ }^{11}$ com 8 mulheres com DP, uma se encontrava no Estágio 2, quatro no Estágio 2,5 e três no Estágio 3; salienta-se que naquele estudo, utilizou-se a Escala de Classificação de Incapacidade de Hohen \& Yahr modificada, porém, neste estudo utilizou-se a clássica de 1967, por isso, a diferença na numeração dos estágios.

Quanto à sintomatologia, o indivíduo portador de DP clássica exibe uma combinação de três sinais: rigidez, bradicinesia e tremor ${ }^{5,12,13}$ o que está em consonância com os achados desta pesquisa. Alterações posturais também são um dos sintomas primários da $\mathrm{DP}^{4,10}$. Ainda, neste estudo, todos os sujeitos referiram dificuldade em realizar movimentos; esta lentidão geral nas atividades de vida diária (AVD's) é uma das características da patologia ${ }^{9,14}$.

A DP pode apresentar comorbidade com depressão em até $50 \%$ dos pacientes acometidos ${ }^{15}$. Nesta 
pesquisa, todos os sujeitos referiram depressão, sendo que todos utilizavam antidepressivos, além disso, a depressão é um dos sintomas mais impactantes na rotina de um parkinsoniano, com tendência ao afastamento social ${ }^{15,16}$.

Em relação à postura corporal, a postura clássica da DP é a de flexão da cabeça, cifose torácica, protração e abdução de ombro, e flexão dos braços 4,8,17 com repercussão na respiração, base para a fonação. Neste estudo, $100 \%$ dos indivíduos apresentaram hiperlordose cervical com flexão da cabeça, $80 \%$ hipercifose dorsal, $80 \%$ protração de ombros e $40 \%$ com semi-flexão de joelhos; sendo que as três primeiras alterações repercutem na produção vocal e da fala ${ }^{1,7,18}$.

Sabe-se que alterações posturais de cabeça, especialmente anteriorização, limitam os movimentos da mandíbula e da própria cabeça, interferindo na produção vocal, uma vez que geram desvantagem biomecânica da musculatura dessa região devido às estreitas relações anatomofuncionais do sistema estomatognático com a região cervical e cintura escapular e ainda devido à rigidez associada à postura em flexão do tronco, presente na DP, pode haver encurtamento dos músculos respiratórios, especialmente do diafragma e assim, afetar a produção da voz e da fala ${ }^{7,9,14,18}$.

Relacionado aos dados fonoaudiológicos, o parkinsoniano apresenta prejuízo peculiar da expressão verbal, observando-se monotonia de freqüência e intensidade, insuficiência prosódica, caracterizada por ausência de variação de tom e altura, disfluência, alteração da velocidade e pausas inadequadas ${ }^{1,2,4,5,12,19}$ as quais repercutem na comunicação verbal e, por conseguinte, na qualidade de vida do indivíduo da DP. Neste estudo, apenas um sujeito apresentou velocidade lenta (S4), encontrando-se no Estágio III, o que está em consonância com estudos que referem que alterações fonoaudiológicas aumentam sua intensidade e freqüência de ocorrência com a duração e evolução da doença ${ }^{4,8,9}$. Contudo, outros autores referem que tais alterações podem estar presentes em fases precoces $^{2,12,14}$, o que não se verificou nesta pesquisa, já que a maioria dos sujeitos (quatro) apresentou velocidade adequada e encontravam-se classificados no Estágio I. Também é importante ressaltar que a velocidade depende dos processos motores ou neurofisiológicos. Assim, sua modificação na DP é variável, visto que os parkinsonianos podem apresentar períodos de rapidez ou lentidão ${ }^{1,18,19}$.

Referente à fluência verbal, a literatura aponta correlação com a intensidade da enfermidade ${ }^{4,5,7,13}$, contudo, nesta pesquisa, o único sujeito que apresentou disfluência (S1) encontra-se no estágio inicial e apresenta hemicorpo esquerdo afetado, ao passo que um dos sujeitos (S2) do estudo, classificado no es- tágio com maior comprometimento motor, ambos hemicorpos comprometidos, não apresentou alteração na fluência. Desta forma, é possível que não haja uma relação absoluta entre as manifestações fisioterapêuticas e disártricas na DP ${ }^{8,9,20}$. É importante considerar que a fluência é uma capacidade que cabe aos dois hemisférios, no entanto, é distribuída de forma distinta, sendo que indivíduos com lesão à direita, tendem a apresentar maior comprometimento nesta função.

Neste estudo, quanto à prosódia lingüística, na fala espontânea, observou-se que a maioria dos sujeitos apresentou monotonia nas sentenças interrogativa e exclamativa, em consonância com autores que destacam diminuição da acentuação no contexto da fala e redução na entonação na DP ${ }^{1,2,4,9,16}$, mas, na imitação, todos apresentaram adequação.

Quanto à sentença afirmativa, quatro indivíduos, todos em diferentes estágios, não apresentaram alteração, possivelmente em decorrência da linearidade apresentada neste tipo de sentença, que requer menor diferenciação na prosódia, uma vez que a mesma demarca menor expressividade e um padrão neutro ${ }^{16,21}$.

$\mathrm{Na}$ DP, a monotonia vocal é freqüente e degrada os sentidos referencial e semântico da mensagem verbal $^{4,7,8,14}$. Na presente pesquisa, ao se comparar prosódia lingüística espontânea e automática, observou-se que todos os sujeitos apresentaram melhor resultado na automática, visto que foram solicitados a repetir sentenças interrogativas, exclamativas e afirmativas. A partir do melhor desempenho na imitação, é possível traçar um paralelo com o método Lee Silverman Voice Treatment (LSVT), específico para a DP ${ }^{8}$, que enfoca principalmente a voz, através da auto-percepção do paciente e do comando verbal do terapeuta.

Segundo a Teoria Dicotômica da Entonação ${ }^{22}$, a prosódia emocional ou afetiva (que expressa alegria, tristeza, raiva) está sob responsabilidade do hemisfério direito e a prosódia lingüística ou proposicional (responsável pela estruturação interna das sentenças) está relacionada ao esquerdo. Contudo, alguns autores afirmam que o hemisfério direito também está envolvido na prosódia lingüística, visto que a prosódia em si não é controlada apenas por um único hemisfério ${ }^{5,9,20,22}$. Diante dessa situação, pode-se sugerir que os sujeitos com piores desempenhos na prosódia (S1 e S5), ainda que com hemicorpos esquerdos afetados e similares alterações corporais, apresentaram distinção na performance lingüística e emocional, evidenciando que a prosódia é dual e complexa.

É sabido que a prosódia emocional adequada possibilita ao indivíduo a expressão do conteúdo emocional, contudo, na DP, há uma redução na tessitura da voz falada, o que transfere ao ouvinte uma qualidade vocal monótona, reduzindo a efetividade da co- 
municação ${ }^{4,5,11,23}$. Há perda de entonação e cadência naturais que conferem à fala sua musicalidade e expressão emocional, especialmente em "sentenças sentimentais" 10,20,23,24.

Em relação à prosódia emocional, a maioria dos sujeitos do presente estudo evidenciou adequação em quase todos os sentimentos avaliados, em discordância com autores que afirmam ocorrer, na $\mathrm{DP}$, perda de controle dos acentos entonativos da palavra espontânea, gerando redução na tonalidade afetiva e emocional da produção ${ }^{4,13,20,23}$. No entanto, como já comentado anteriormente, pode-se pensar que há grande dependência das alterações apresentadas pelos pacientes com DP, conforme o estágio da doença em que se encontram, salientando-se que, nesta pesquisa, a maioria foi classificada no Estágio I. Ainda, as características fonoaudiológicas não possuem demarcações em relação a cada estágio da doença, por isso, os casos devem ser analisados qualitativamente ${ }^{4,20}$.

A linguagem é uma habilidade complexa e multifacetada que se expressa por meio de gestos, tom de voz e postura corporal, sendo dependente de aspectos emocionais e tendo componentes afetivos manifestados através da prosódia ${ }^{6,12,16}$.

A aprendizagem da linguagem emocional se inicia antes da fala, através do olhar, expressão facial e atividade gestual, sendo considerada primitiva; ao passo que o código lingüístico é arbitrário e se baseia no conhecimento adquirido em relação a objetos, ações, locais, propriedades ${ }^{20,22}$. Tais afirmações podem oferecer subsídios aos resultados desta pesquisa em que a maioria dos indivíduos apresentou melhor performance na prosódia emocional. Ou seja, conseguiram transmitir o conteúdo implícito na expressão de sentimentos e pensamentos de forma natural.

Na relação entre os estágios, hemicorpo afetado e prosódia, três indivíduos (S1, S3 e S5), todos no Estágio I, apresentaram distinção na performance da prosódia lingüística espontânea e da prosódia emocional. O indivíduo S1, 45 anos, apresentou pior desempenho na prosódia lingüística. É possível que alterações prosódicas aumentem sua gravidade com a duração e evolução da doença ${ }^{2,23}$; tais dados da literatura não corroboram os dados deste sujeito, visto que ele se encontra no primeiro estágio de evolução da doença; porém, é importante considerar o tempo do diagnóstico da doença, em torno de 12 anos e ainda o fato de que o hemicorpo comprometido é o esquerdo e historicamente o hemisfério direito o responsável pelos acontecimentos motores e sensoriais, entretanto, ressalta-se a complexidade do cérebro e as interconexões entre os hemisférios. Considerando-se esses comentários, possivelmente, o déficit deveria ter ocorrido nas tarefas de prosódia emocional. Entretanto, pode-se sugerir con- sonância com autores que referem que parece haver pouca correspondência entre a severidade da disartria, duração da DP e severidade dos sintomas nos membros ${ }^{1,20}$.

O indivíduo S3, 52 anos, apresentou melhor performance na prosódia lingüística espontânea, com adequação em todas as sentenças, com hemicorpo direito afetado, o que sugeriria comprometimento no hemisfério esquerdo e conseqüentemente na prosódia lingüística. Esses dados divergem da literatura, pois os parkinsonianos tendem a apresentar melhor desempenho em exercícios como leitura ou repetição de listas de palavras ou sentenças, contudo, no decorrer das conversações, sua fala se deteriora ${ }^{13}$. Nesta pesquisa, é possível que este sujeito tenha apresentado uma performance melhor em virtude da atenção dispensada as suas próprias falas, ao interesse na tarefa e possivelmente, em virtude de que o sexo feminino é mais exposto a contingências de aprendizagem sobre as emoções, devido a práticas culturais que valorizam desempenhos socialmente mais adequados e maior sensibilidade ${ }^{24}$. Além disso, há uma imprevisibilidade no comprometimento da disartria, já que, pode ocorrer uma rápida e inexorável deterioração ou ainda um declínio progressivo com períodos de remissão ${ }^{25-27}$.

Já o indivíduo S5, 37 anos, apresentou pior desempenho na prosódia emocional, possivelmente, em decorrência do chamado "parkinsonismo de início precoce" que acomete pacientes abaixo de 40 anos e tende a gerar sintomatologia mais grave ${ }^{28}$. Pode-se ainda pensar que, se o hemicorpo comprometido esquerdo encontra-se afetado, possivelmente há déficit no hemisfério direito que se correlaciona com a prosódia emocional. Também se pode afirmar que os déficits nas disartrias dependem da idade do surgimento da DP, etiologia e área neuroanatômica afetada ${ }^{1,19,20,29}$, além disso, pode-se considerar que profissões que exigem comando verbal constante podem interferir no desempenho da prosódia lingüística.

\section{CONCLUSÃO}

A Doença de Parkinson apresenta sintomatologia variada, de evolução progressiva, única para cada indivíduo, com grandes alterações típicas na postura corporal. Os padrões de disartria hipocinética apresentada na DP, incluindo a prosódia, são altamente variáveis dependendo da gravidade da doença, tipo de tarefa, condições pré-existentes e/ou substrato neurológico afetado. Neste estudo, não se verificou uma interrelação absoluta entre a postura corporal e a prosódia, provavelmente, em decorrência da complexidade fisiopatológica e do pequeno número de sujeitos da pesquisa. 


\section{ABSTRACT}

Purpose: to investigate the relationship between body posture and prosody in patients with Parkinson Disease. Methods: the study was carried out with five patients (four males and one female) from Santa Maria, Rio Grande do Sul, Brazil, by means of cross-section study, in 2006. Evaluations of linguistic and emotional prosody as well as analysis of body posture were carried out. The statistical analysis was descriptive. Results: the subjects of this study were four men and one woman aged between 37 and 53 years. Three of these patients were classified in stage I of the disease; one in the stage III and the other one in the stage IV, according to the classification of Hohen \& Yahr motor function. All of them were under medication and presenting the signals of the characteristic triad of such pathology: rigidity, tremor and bradykinesia, as well as the typical alterations of body posture. In the comparison between linguistic prosody and emotional prosody, subjects showed the best performance in emotional prosody and no associations among the stages of the disease and the alterations on body posture and prosody were evidenced. Conclusion: body posture alterations are the characteristic signals of Parkinson Disease as well as the disorders related to linguistic and emotional prosody. The occurrence of posture alterations was high in patients with Parkinson disease. Subjects showed better performance in emotional prosody. There were no evidences that the stages of the disease were related to prosody or body posture alterations.

KEYWORDS: Cross-Sectional Studies; Parkinson Disease; Posture; Physical Therapy Modalities; Speech Therapy

\section{REFERÊNCIAS}

1. Schulz GM, Grant MK. Effects of speech therapy and pharmacologic and surgical treatments on voice and speech in Parkinson's disease: a review of the literature. J Commun Disord. 2000; 33(1):59-88.

2. Le Dorze G, Dionne L, Ryalls J, Julien M, Ouellet $L$. The effects of speech and language therapy for a case of dysarthria associated with Parkinson's disease. Eur J Disord Commun. 1992; 27(4):313-24. 3. André ES. Moléstia de Parkinson. Fisiot Mov. 2004; 17(1):11-24.

4. Goede CJ, Keus SH, Kwakkel G, Wagenaar RC. The effects of physical therapy in Parkinson's Disease: a research synthesis. Arch Phys Med Rehabil. 2001; 82(4):509-15.

5. Barros ALS, Silveira EGC, Souza RCM, Freitas LC. Uma análise do comprometimento da fala em portadores de doença de Parkinson. Neuroci. 2004; 12(3):123-9.

6. Behrens SJ. Characterizing sentence intonation in a right hemisphere-damaged population. Brain Lang. 1989; 37(2):181-200.

7. Kendall FP, Creary EK. Força muscular em relação à postura. In: Kendall FP. Músculos, provas e funções. São Paulo: Manole; 1995.

8. Conley SC, Kirchner JT. Parkinson's disease: the shaking palsy. Underlying factors, diagnostic considerations and clinical course. Postgrad Med. 1999; 106(1):39-50.

9. Dias AE, Limongi JCP. Tratamento dos distúrbios da voz na doença de Parkinson, o método Lee Silverman. Arq Neuropsiquiatr. 2003; 61(1):61-6.
10. Silveira DN, Brasolotto AG. Reabilitação vocal em pacientes com doença de Parkinson: fatores interferentes. Pró-Fono. 2005; 17(2):241-50.

11. Santos L. Perfil do paciente parkinsoniano atendido em ambulatório de um hospital geral universitário da Grande São Paulo. [mestrado]. São Paulo (SP): Universidade Federal de São Paulo; 2001.

12. Azevedo LL, Cardoso P, Reis $C$. Análise acústica da prosódia em mulheres com doença de Parkinson. Arq Neuropsiquiatr. 2003; 61(4):999-1003.

13. Costa AVR. Respiração bucal e postura corporal uma relação de causa e efeito. [monografia]. Rio de Janeiro (RJ): CEFAC - Saúde e Educação; 1999.

14. Lamônica DAC, Saes SO, Paro PMM, Brasoloto AG, Andreza SB. Doença de Parkinson: proposta de protocolo de anamnese. Salusvita. 2003; 22(3):363-71. 15. Jiménez FJ, Gamboa J, Nieto A. Acoustic voice analysis in untreated patients with parkinson's disease. Parkinsonism Related Disord. 1997; 3(2):111-6.

16. Fahn S. Description of Parkinson's disease as clinical syndrome. Ann NY Acad Sci. 2003; 991:1-14. 17. Teng CT, Humes EC, Demetrio FN. Depressão e comorbidades clínicas. Rev Psiq Clín. 2005; 32(3):149-59.

18. De Letter M, Santens P, Van Borsel J. The effects of levodopa on word intelligibility in Parkinson's disease. J Commun Disord. 2005; 38(3):187-96.

19. Guimarães J, Alegria P. O parkinsonismo. Med Int. 2004; 11(2):109-14.

20. Krakauer LRH. Relação entre respiração bucal e alterações posturais em crianças: uma análise descritiva. [mestrado]. São Paulo (SP): Pontifícia Universidade Católica de São Paulo; 1997. 
21. Carro OT, León M, Alvarez E, Alvarez L, Maragato C, Rireva O. Particularidades articulares de la disartria Parkinsoniana. Rev Mex Neuroci. $2001 ; 2(4): 235-9$.

22. Locco J. La production des occlusives dans la maladie de Parkinson. [docteur]. Marseille (France): L'Universite Aix-Marseille. 2005. 338 p . Disponível em: URL: http://aune.Ipl.univ-aix.fr/ Acesso em: 10 jan 2007. 23. Martinet A. Acento e tons. In: Martinet A. A lingüística sincrônica. Rio de Janeiro: Temo Brasileiro; 1974.

24. Iliovitz ER. Pausa e domínios prosódicos nas disartrias. [doutorado]. Campinas (SP): Universidade Estadual de Campinas; 2005.
25. Garcia-Serpa FA, Meyer SB, Del Prette ZAP. Origem social do relato de sentimentos: evidência empírica indireta. Rev Bras Ter Comport Cogn. 2003; 5(1):21-9. 26. Ferreira LP, Befi-Lopes DM, Limongi SC, organizador. Tratado de fonoaudiologia. São Paulo: Roca; 2004.

27. Aguiar RA, López HMN, Pedroso IP. Una alternativa para la prevención de los trastornos del lenguaje em la enfermedad de Parkinson. Rev Mex Neuroci. 2005; 6(1):22-5.

28. Arcusa MJL, Álvarez JG. Medida de la inteligibilidad em el habla disártrica. Rev Logoped Foniatr Audiol. 2004; 24(1):33-43.

29. Barbosa ER, Sallem FAS. Doença de Parkinson: diagnóstico. Neuroci. 2005; 13(3):158-65.

RECEBIDO EM: 08/05/2007

ACEITO EM: 09/09/2007

Endereço para correspondência:

Rua Visconde de Pelotas, 517

Santa Maria - RS

CEP: $97010-440$

Tel: (55) 32252435

E-mail: nandaf_pg@yahoo.com.br 